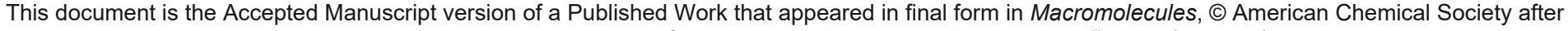
peer review and technical editing by the publisher. To access the final edited and published work see https://doi.org/10.1021/ma0008544

\title{
Stabilization of Pluronic P-105 Micelles with an Interpenetrating Network of $N, N$-Diethylacrylamide
}

\author{
John D. Pruitt \\ Chemical Engineering Department, Brigham Young University, Provo, Utah 84602
}

Ghaleb Husseini

Chemical Engineering Department, Brigham Young University, Provo, Utah, 84602

Natalya Rapoport

Center for Biopolymers at Interfaces, University of Utah, Salt Lake City, Utah 84112

William G. Pitt*

Chemical Engineering Department, Brigham Young University, Provo, Utah 84602

Received May 17, 2000; Revised Manuscript Received October 4, 2000

\begin{abstract}
N, N$-Diethylacrylamide (NNDEA) was polymerized in the presence of Pluronic P-105 micelles. The polymerizations resulted in an interpenetrating network of poly(NNDEA) and P-105 that stabilized the micelles at concentrations below the critical micellar concentration of free P-105. The NNDEA was cross-linked with $N, N^{\prime}-$ bis(acryoyl)cystamine (BAC), and the degree of micellar stability was determined using dynamic light scattering and the fluorescent probe diphenylhexatriene (DPH). The increased micellar stability was not permanent and disappeared over a time period of days to weeks.
\end{abstract}

\section{Introduction}

Pluronic P-105 (BASF Corp) is a triblock copolymer consisting of blocks of poly(propylene oxide) (PPO) and poly(ethylene oxide) (PEO) in the form $\mathrm{PEO}_{37}-\mathrm{PPO}_{56} \mathrm{PEO}_{37}$. P-105 has a broad critical micellar concentration $(\mathrm{cmc})$ around $0.3 \mathrm{wt} \%$ at room temperature and just over $0.001 \mathrm{wt} \%$ at $37^{\circ} \mathrm{C} .{ }^{1}$ At concentrations above the cmc, P-105 self-assembles into micelles with a hydrophobic PPO core and a hydrophilic PEO corona. ${ }^{2-4}$ Pluronics have been shown to sequester hydrophobic drugs such as doxorubicin, thereby protecting cells from the drug. ${ }^{4-9}$ The use of Pluronic as a drug delivery vehicle has also been shown to reverse multidrug resistance by inhibiting the P-glycoprotein pump, which is overexpressed in resistant cells. ${ }^{10,11}$ PEO coatings on particles can also slow the rate at which particles are cleared from the blood because it resists protein adsorption and thus protects the particles from clearance by the reticuloendothelial system. ${ }^{12-14}$

Our previous work has shown a synergism between doxorubicin loaded P-105 micelles and low-frequency ultrasound. 5,7,9,15 The characteristics of Pluronic micelles make them an attractive candidate as a drug delivery system, but one of the problems encountered with the use of Pluronic P-105 is that the micelles disassociate at low concentration and are no longer able to sequester hydrophobic drugs. This work focuses on the stabilization of Pluronic micelles by forming an interpenetrating network of a thermoresponsive polymer, poly(N,Ndiethylacrylamide) (NNDEA), within the hydrophobic micellar core. Poly(NNDEA) has a lower critical solution temperature (LCST) of $28{ }^{\circ} \mathrm{C}$. Below the LCST, poly(NNDEA) exists in a hydrophilic expanded state in aqueous solutions while above the LCST, poly(NNDEA). collapses into a hydrophobic state that is insoluble in water. This property may allow the poly(NNDEA) to stabilize the micelles at temperatures above its LCST while expanding to facilitate drug loading at temperatures below the LCST.

\section{Materials and Methods}

2.1. Materials. Pluronic P-105 was provided by BASF Corp. (Mount Olive, NJ). $N, N$-Diethylacrylamide (NNDEA) was obtained from Polysciences (Warrington, PA). $N, N^{\prime}$-Bis(acryoyl)cystamine (BAC) was obtained from Fluka (Milwaukee, WI), and 2,2'-azobis(isobutyronitrile) (AIBN) was obtained from Aldrich (Milwaukee, WI). 1,6-Diphenyl-1,3,5-hexatriene (DPH) was obtained from Molecular Probes (Eugene, OR) and was used as received.

2.2. Relative Viscosity Measurements. Pluronic micelles undergo a sphere-to-rod phase transition at elevated temperatures. ${ }^{16}$ This transition is manifested by a sharp increase in the viscosity of the solution. To ensure that polymerizations were conducted in the spherical temperature region, the relative viscosity of a $10 \mathrm{wt} \% \mathrm{P}-105$ solution was measured with a capillary viscometer (Schott-Gerate). The capillary viscometer apparatus was placed in a temperature-controlled water bath, and the time necessary for the meniscus to descend through the capillary region was measured at each temperature for both distilled water and a $10 \mathrm{wt} \% \mathrm{P}-105$ solution.

2.3. Polymerizations. A $40 \mathrm{~mL}$ aliquot of double distilled water containing $10 \mathrm{wt} \%$ Pluronic P-105 was added to a roundbottom flask. NNDEA monomer was added to give concentrations ranging from 0 to $1 \mathrm{wt} \%$ monomer. BAC was added as a cross-linking agent to give BAC:NNDEA mole ratios ranging from 0 to 1:20. AIBN was added as an initiator, and the flask was then connected to a water condenser and purged with nitrogen for at least $1 \mathrm{~h}$. The system was then allowed to polymerize 
for $24 \mathrm{~h}$ at $65{ }^{\circ} \mathrm{C}$ with magnetic stirring and a continuous nitrogen purge. Polymerization samples were diluted with double distilled water when lower concentrations were needed for testing.

2.4. Molecular Weight Determination. The molecular weight of non-cross-linked poly(NNDEA) was measured by gel

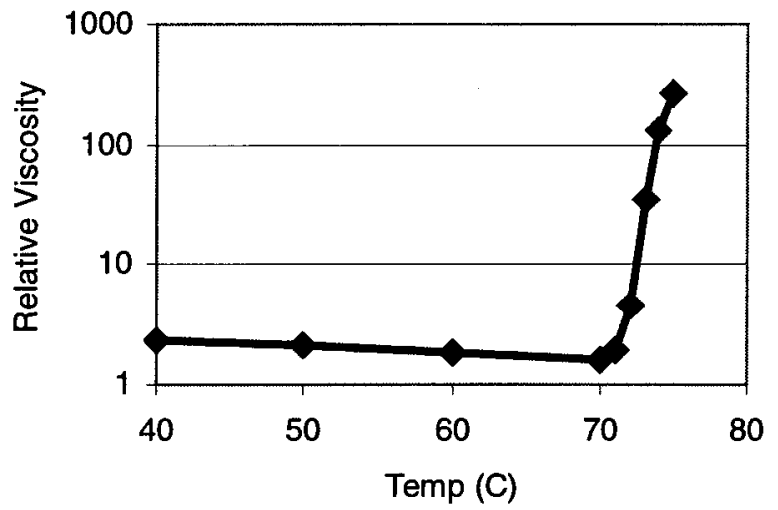

Figure 1. Relative viscosity of a $10 \mathrm{wt} \% \mathrm{P}-105$ solution as a function of temperature (relative to water).

permeation chromatography using a Waters GPC system (Milford, MA) (model 515 pump with styragel columns and a model 2410 refractive index detector). Polymerization samples were dried, dissolved in tetrahydrofuran at a concentration of $2 \mathrm{mg} / \mathrm{mL}$, and filtered through a $0.2 \mu \mathrm{m}$ Teflon filter before being injected into the GPC system. Molecular weights were determined using polystyrene calibration standards and Water's Millennium ${ }^{32}$ software.

2.5. Turbidity Measurements. A UV-vis-NIR spectrophotometer (Cary 5E, Varian) was used to measure the turbidity of the polymerized solutions as a function of temperature in order to determine the LCST of poly(NNDEA) and to determine whether any particle aggregation had occurred in the stabilized micelles. Samples were placed in a temperature-controlled cuvette holder, and the temperature was ramped from 20 to $40{ }^{\circ} \mathrm{C}$ at a rate of $0.5^{\circ} \mathrm{C} / \mathrm{min}$. The absorbance was measured at 600 $\mathrm{nm}$.

2.6. Particle Size Determination. Dynamic light scattering (DLS) experiments were conducted using a BI 200 spectrometer (Brookhaven Instruments) with a BI 2030 AT 72channel autocorrelator. The temperature was controlled with a recirculating bath, and measurements were taken at both 37 and $20^{\circ} \mathrm{C}$. All samples were filtered $(0.2 \mu \mathrm{m})$ before analysis.

2.7. Particle Stabilization and Microenvironment. The critical micellar concentration $(\mathrm{cmc})$ and micellar stability were studied using a luminescence spectrometer (LS50B, PerkinElmer) with diphenylhexatriene (DPH) as the fluorescent probe. The emission spectrum of DPH is highly dependent upon the hydrophobicity of the local environment, and DPH has almost no fluorescence in an aqueous solution while it is highly fluorescent in a hydrophobic environment. ${ }^{17}$ This makes DPH very useful for determining whether a hydrophobic environment is present. Polymerized samples were serially diluted in double distilled water to give Pluronic P-105 concentrations ranging from 10 to $0.0001 \mathrm{wt} \%$. A stock solution of DPH in tetrahydrofuran (THF) was added to an empty vial, and the THF was evaporated, leaving $2 \mu \mathrm{g}$ of DPH. A $20 \mathrm{~mL}$ aliquot of the diluted polymerization samples was then added to the vial. It was anticipated that in the highly dilute polymerization samples not all of the DPH would dissolve, and a saturated solution would result. Concentrated solutions containing many micelles should dissolve all of the DPH resulting in a maximum DPH concentration of $0.1 \mu \mathrm{g} / \mathrm{mL}$. The samples were transferred to a quartz cuvette and excited at $360 \mathrm{~nm}$; the emission at $430 \mathrm{~nm}$ was measured. The temperature was controlled with a recirculating thermostatic bath connected to the cuvette holder.

\section{Results and Discussion}

3.1. Relative Viscosity. Measurements of the relative viscosity of a $10 \mathrm{wt} \% \mathrm{P}-105$ solution showed a sharp increase in the viscosity at a temperature of $71{ }^{\circ} \mathrm{C}$ (see Figure 1). The increase in viscosity corresponds to the phase change from spherical micelles to rodlike structures. 


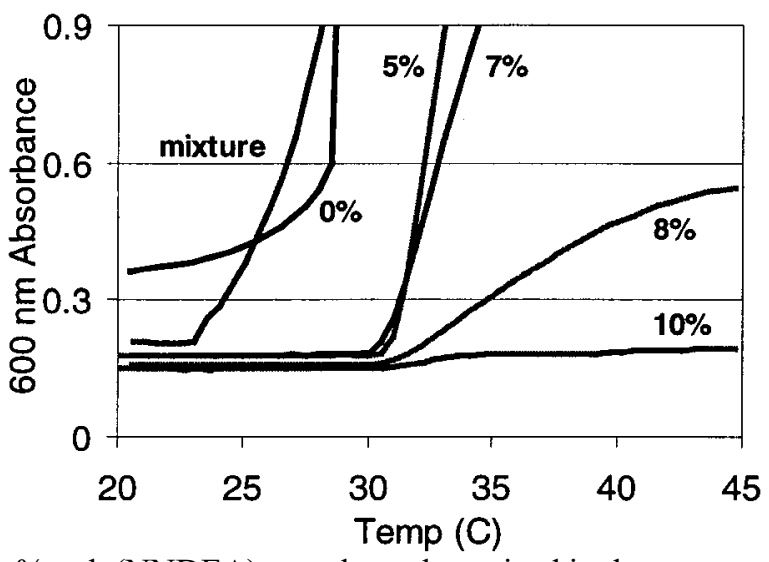

Figure 2. Turbidity of $1 \mathrm{wt} \%$ poly(NNDEA) samples polymerized in the presence of increasing wt \% concentrations of P-105 (shown on graph). The line marked "mixture" is a physical mixture of $1 \mathrm{wt} \%$ poly(NNDEA) and $10 \mathrm{wt} \% \mathrm{P}-105$. The temperature was increased at a rate of $0.5^{\circ} \mathrm{C} / \mathrm{min}$.

Polymerizations were conducted at temperatures below the sphere-to-rod transition to ensure that spherical micelles would be present.

3.2. Molecular Weight. NNDEA $(1 / 2 \mathrm{wt} \%)$ was polymerized in the presence of $10 \mathrm{wt} \% \mathrm{P}-105$ without any cross-linker and then run on a GPC column. An additional peak (when compared to pure P-105) was visible at a molecular weight of 22000 Da. This corresponds to a chain length of about 170 repeat units for the poly(NNDEA).

3.3. Turbidity Measurements. The collapse of poly(NNDEA) into a hydrophobic state at its LCST can be observed as an increase in the turbidity of an aqueous solution as the resulting particulates scatter visible light. The absorbance of $600 \mathrm{~nm}$ light was used as a means of determining whether the poly(NNDEA) had aggregated into particles large enough to scatter light. Figure 2 shows a sharp increase in turbidity at $28{ }^{\circ} \mathrm{C}$ for $1 \mathrm{wt} \%$ non-cross-linked NNDEA polymerized in water $(0$ wt $\%$ P105). When NNDEA was polymerized in the presence of 5\% P-105, the transition temperature shifted to a higher temperature of about $31{ }^{\circ} \mathrm{C}$, and the maximum slope of the transition was not as steep. At higher P-105 concentrations the transition remained at $31{ }^{\circ} \mathrm{C}$, but the slope of the transition was not as steep and the solution did not become as turbid. At a concentration of 10 wt $\%$ P-105 and $1 \mathrm{wt} \%$ NNDEA there was almost no increase in the turbidity upon heating. The fact that only a small increase in turbidity was visible suggested that most of the NNDEA had polymerized within the micellar cores, which limited the aggregation of the particles upon thermally induced collapse. However, the $1 \%$ NNDEA/10\% P-105 solution would clog a 0.2 $\mu \mathrm{m}$ filter, and light scattering measurements showed that large particles were present. Samples polymerized with $1 / 2$ wt $\%$ NNDEA in P-105 did not clog a $0.2 \mu \mathrm{m}$ filter, and no increase in turbidity occurred upon heating even at a P-105 concentration of 5\% (data not shown). The turbidity of a physical mixture of 10\% P-105 and 1\% poly(NNDEA) is also shown in Figure 2 . The physical mixture showed a much larger increase in turbidity than the sample containing 1 wt \% NNDEA polymerized in the presence of $10 \% \mathrm{P}-105$. The magnitude of the turbidity increase and its transition temperature were much closer to the magnitude and transition temperature of $1 \mathrm{wt} \%$ poly(NNDEA) without any P-105 present than to the $1 \%$ NNDEA/10\% P-105

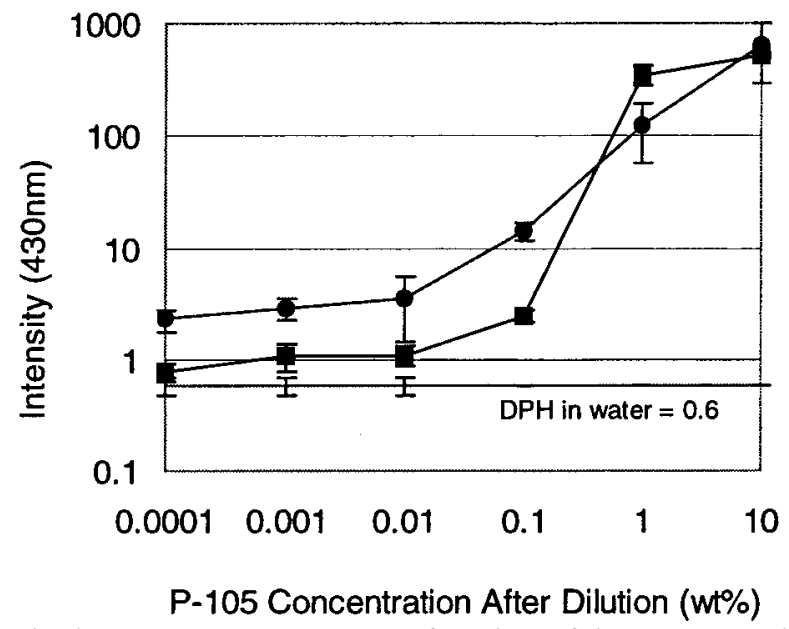

Figure 3. Emission of DPH excited at $360 \mathrm{~nm}$ at $24^{\circ} \mathrm{C}$ as a function of the concentration of P-105 and poly(NNDEA)/ P-105. The emission of DPH in distilled water is shown as ahorizontal line. Key: $9, \mathrm{P}-105 ; \mathrm{b}, 1 / 2$ wt \% poly(NNDEA)/ P-105.

sample. The large difference in turbidity between the sample polymerized in the presence of $10 \% \mathrm{P}-105$ and the sample that was mixed with P-105 after polymerization indicates that it is not just the presence of P-105 that causes the difference in 
turbidity. In the physical mixture of poly(NNDEA) and P-105, the Pluronic was not able to sequester all of the poly(NNDEA), and after several days, settling of the poly(NNDEA) was visible in the physical mixture sample. No visible settling occurred over 15 months in the sample where NNDEA was polymerized in the presence of P-105.

3.4. Stability Measurements with DPH. The fluorescent emission spectrum of DPH was used to measure the $\mathrm{cmc}$ of Pluronic P-105 and to demonstrate the presence of a hydrophobic environment in the stabilized particles. This was done at concentrations below the cmc of free P-105 because DPH only fluoresces when it is in a hydrophobic environment. Figure 3 shows data at room temperature (measured at $24{ }^{\circ} \mathrm{C}$ in the cuvette) for free P- 105 and $1 / 2 \mathrm{wt} \%$ NNDEA $/ 10 \mathrm{wt} \% \mathrm{P}-105$ stabilized particles. A sharp drop in the emission intensity of DPH was seen immediately upon dilution of P-105 to a concentration below the cmc. A 1 order of magnitude dilution of P-105 resulted in a decrease of greater than 2 orders of magnitude in the emission intensity at concentrations near the cmc. The drop in emission intensity is due to both the presence of a less hydrophobic environment as micelles quickly dissociate and a decrease in the solubilization of DPH. At $0.0001 \mathrm{wt} \% \mathrm{P}-105$ the emission intensity of the free P-105 sample was only slightly above the emission intensity observed for a saturated solution of DPH in distilled water. The $1 / 2$ wt $\%$ NNDEA/10 wt \% P-105 sample does not show as sharp of a decline in emission upon dilution, and the emission intensity remains significantly higher than the P-105 sample even at extreme dilution. The emission intensities of multiple polymerization samples and free P-105 samples were measured, and 95\% confidence intervals are shown in Figure 3.

To investigate the change in particle stability over time, a ratio of the emission of the "stabilized" samples to the emission of a P-105 sample was taken at a 100 000-fold dilution (0.0001 wt \% P-105). Figure 4

shows the emission ratio of $1 / 2$ wt $\%$ NNDEA/P-105 to free P-105 at both 24 and $37^{\circ} \mathrm{C}$ as a function of the time

that the samples have been stored in a diluted state. Initially, the emission ratio of the stabilized particles was large because the DPH emission intensity from the poly(NNDEA)/P-105 sample was much larger than for free P-105. This indicates that at high dilution the local environment of the stabilized particles is more hydrophobic than the local environment of free P-105. Over several days the difference in emission between the "stabilized" particles and P-105 disappeared, which indicates that the increased hydrophobicity of the stabilized particles is only temporary. This may be due to disentanglement of the P-105 molecules from the interpenetrating network of poly(NNDEA), which allowed the micelles to disassociate over time. The emission ratio of the samples stored at $37^{\circ} \mathrm{C}$ appears to approach 1.0 faster than the samples stored at room temperature. This may be due to increased thermal motion at the higher temperature. The initial emission ratio is lower at $37{ }^{\circ} \mathrm{C}$ than at $24{ }^{\circ} \mathrm{C}$, even though the emission intensity of the poly(NNDEA)/P-105 sample is higher at $37^{\circ} \mathrm{C}$, because free $\mathrm{P}-105$ also has a larger emission intensity at the higher temperature.

3.5. Dynamic Light Scattering. Dynamic light scattering measurements were used to determine whether particles were detectable at concentrations below the cmc of Pluronic. At dilute concentrations at both 25 and $37^{\circ} \mathrm{C}$, no particles were detected in P-105 solutions, whereas particles were evident in the $1 / 2 \mathrm{wt} \%$ poly(NNDEA)/P-105 sample at the same dilutions.

Samples containing $1 \mathrm{wt} \%$ NNDEA polymerized in $10 \mathrm{wt} \% \mathrm{P}-105$ resulted in large particles that would clog a $0.2 \mu \mathrm{m}$ filter.

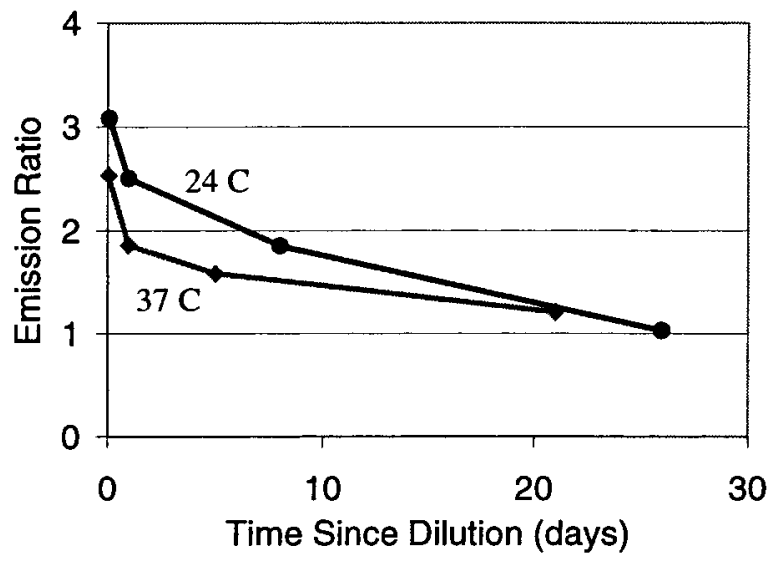

Figure 4. Ratio of DPH emission for poly(NNDEA)/P-105 to P-105 as a function of time at 100000 -fold dilution (0.0001 wt $\% \mathrm{P}-105)$ stored and measured at either room temperature or $37^{\circ} \mathrm{C}$.

This was unexpected since the particles had not shown a large increase in turbidity upon heating. Polymerizations of $1 / 2 \mathrm{wt}$ $\%$ NNDEA in $10 \mathrm{wt} \% \mathrm{P}-105$ resulted in a product that would pass through a $0.2 \mu \mathrm{m}$ filter. DLS experiments at $25^{\circ} \mathrm{C}$ showed that in the $1 / 2$ wt $\%$ NNDEA/10 wt $\%$ P-105 sample the particles were still larger than free P-105 micelles especially in the undiluted state, indicating that some aggregation into larger particles appears to occur even at $1 / 2 \mathrm{wt} \%$ NNDEA (see Figure 5). Free P-105 particles were not detectable at concentrations below $1 \mathrm{wt} \%$ because the micelles disassociate at concentrations below the cmc. 
After a $10 \mathrm{wt} \% \mathrm{P}-105 / 1 / 2 \mathrm{wt} \%$ NNDEA sample was stored for 2 months, the DLS diameter was the same as for the free P105 sample, indicating that the P-105 disassociated over a period of days to weeks.

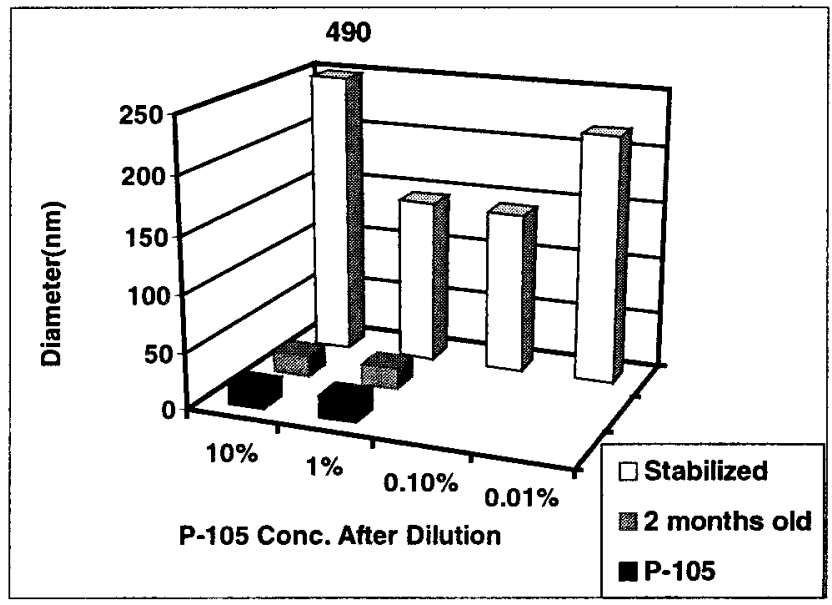

Figure 5. DLS effective diameters for P-105, fresh poly(NNDEA)/P-105, and 2-month-old poly(NNDEA)/P-105 at $25^{\circ} \mathrm{C}$.

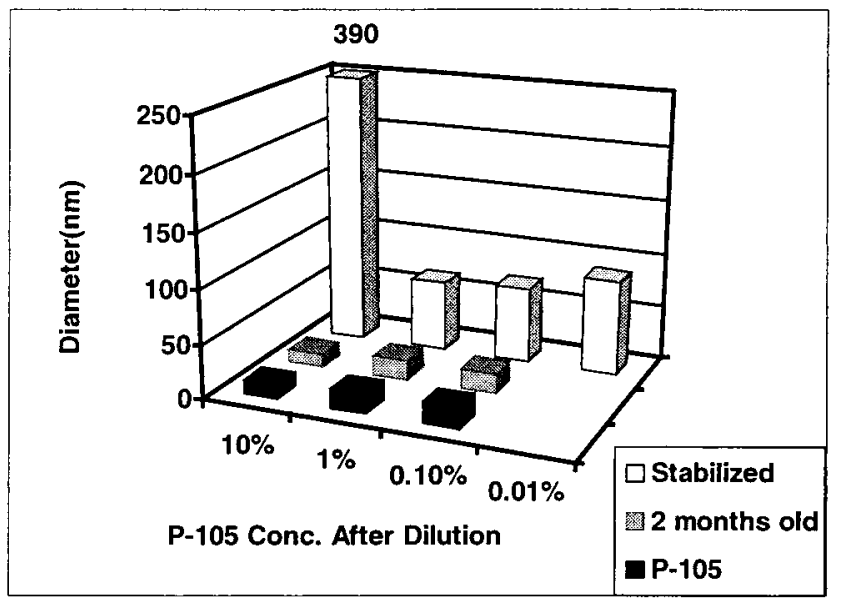

Figure 6. DLS effective diameters for $\mathrm{P}-105$, fresh poly(NNDEA)/P-105, and 2-month-old poly(NNDEA)/P-105 at $37^{\circ} \mathrm{C}$

At $37{ }^{\circ} \mathrm{C}$ the $1 / 2$ wt $\%$ NNDEA $/ 10$ wt $\%$ P-105 particles were substantially smaller than at $25^{\circ} \mathrm{C}$, but some aggregation into larger particles still occurred in the undiluted sample (see Figure 6). The decrease in particle size upon heating is attributed to the collapse of the poly(NNDEA) above its LCST. As the poly(NNDEA) collapses into a hydrophobic state, water is expelled and/ or the polymer chains may be sequestered inside the micellar core instead of expanding into the aqueous environment at lower temperatures. Even at $37^{\circ} \mathrm{C}$ the poly(NNDEA)/P-105 particles were larger than free P-105 micelles. This may be an indication of aggregation or polymer extending outside of the micelles.

At both temperatures the stabilized particles were observed at dilutions below the concentrations where P-105 particles were observed. This suggests that the particles are not disassociating immediately upon dilution and that the micelles have been stabilized by the poly(NNDEA). The increased stabilization disappears over time, and after 2 months there was no difference in size or detectability between the stabilized and unstabilized sample at both 37 and $25^{\circ} \mathrm{C}$.

\section{Conclusion}

Polymerization of NNDEA in the presence of $10 \mathrm{wt} \% \mathrm{P}-105$ results in an interpenetrating network of poly(NNDEA) and P105 within the micellar core. The large differences between samples with NNDEA polymerized in the presence of P-105 and a physical mixture of poly(NNDEA) and P-105 suggest that the NNDEA has polymerized within the micelles. The physical mixture shows a much larger increase in turbidity upon heating, and solid precipitate is visible after several days. The sample with NNDEA polymerized in the presence of P-105 micelles does not show a sharp increase in turbidity upon heating, and no settling is visible. 
The interpenetrating network of poly(NNDEA) appears to temporarily stabilize the micelles at concentrations below their $\mathrm{cmc}$. This is evidenced by the fact that particles are detectable with dynamic light scattering at concentrations below the $\mathrm{cmc}$ of pure P-105; also, DPH fluorescence indicates the presence of a hydrophobic environment at concentrations well below the cmc. Both the increased DPH emission intensity and the detectability of particles with DLS disappear after several weeks, indicating that the stabilization is only temporary.

The poly(NNDEA)/P-105 particles are substantially larger than free P-105 micelles, and this may be due to swelling of the micelles with water or poly(NNDEA) extending out of the micelles into the aqueous phase.

Acknowledgment. Funding for this research was provided by the NIH (CA 76562).

\section{References and Notes}

(1) Alexandridis, P.; Holzwarth, J. F.; Hatton, T. A. Macromolecules 1994, 27, 2414-2425.

(2) Alexandridis, P.; Athanassiou, V.; Hatton, T. A. Langmuir 1995, 11, 2442-2450.

(3) Alexandridis, P.; Hatton, T. A. Colloids Surf. A 1995, 96, 1-46.

(4) Kabanov, A. V.; Batrakova, E. V.; Melik-Nubarov, N. S.; Fedoseev, N. A.; Dorodnich, T. Y.; Alakhov, V. Y.; Nazarova, I. R.; Kabanov, V. A. J. Controlled Release 1992, 22, 141158.

(5) Munshi, N.; Rapoport, N.; Pitt, W. G. Cancer Lett. 1997, 117, 1-7.

(6) Rapoport, N. Y.; Herron, J. N.; Pitt, W. G.; Pitina, L. J. Controlled Release 1999, 58, 153-162.

(7) Rapoport, N. Y.; Herron, J. N.; Pitt, W. G.; Pitina, L. J. Controlled Release 1999, 58, 153-162.

(8) Kwon, G.; Naito, M.; Yokoyama, M.; Okano, T.; Sakurai, Y.; Kataoka, K. J. Controlled Release 1997, 48, 195-201.

(9) Husseini, G. A.; El-Fayoumi, R. I.; O’Neill, K. L.; Rapoport,

N. Y.; Pitt, W. G. Cancer Lett., in press.

(10) Alakhov, V. Y.; Moskaleva, E. Y.; Batrakova, E.; Kabanov, A. V. Bioconjugate Chem. 1996, 7, 209-216.

(11) Venne, A.; Li, S.; Mandeville, R.; Kabanov, A.; Alakhov, V. Cancer Res. 1996, 56, 3626-3629.

(12) Zambaux, M.-F.; Faivre-Fiorina, B.; Bonneaux, F.; Marchal, S.; Merlin, J.-L.; Dellacherie, E.; Labrude, P.; vigneron, C. Biomaterials 2000, 21, 975-980.

(13) Vandorpe, J.; Schacht, E.; Dunn, S.; Hawley, A.; Stolnik, S.; Davis, S. S.; Garnett, M. C.; Davies, M. C.; Illum, L. Biomaterials 1997, 18, 1147-1152.

(14) Quellec, P.; Gref, R.; Dellacherie, E.; Sommer, F.; Tran, M. D.; Alonso, M. J. J. Biomed. Mater. Res. 1999, 47, 388-395.

(15) Rapoport, N. Colloids Surf. B 1999, 16, 93-111.

(16) Schillen, K.; Brown, W.; Johnson, R. M. Macromolecules 1994, 27, 4825-4832.

(17) Chattopadhyay, A.; London, E. Anal. Biochem. 1984, 23, 408-412.

MA0008544 